\title{
Constructing Masculinities in the National Rugby League's Footy Show
}

The research uses content analysis and inclusive masculinity theory in order to explore and explain the construction of esteemed and subjugated masculinities within the context of Australia's National Rugby League's (NRL) Footy Show. Results suggest that despite previous research on NRL players, which finds inclusive masculinities dominate, this television show instead attempts to construct orthodox versions of masculinity. We suggest that the Footy Show thus occupies a liminal state in regards to masculinities; attempting to portray, construct and endorse orthodox masculinities, whilst showcasing athletes that more closely align with the social trends of inclusive masculinities.

Key Words: Masculinity, media, men, sport, Rugby League. 


\subsection{Introduction}

Organised team sports have often been considered a key vehicle for the production of a socially valued archetype of heteromasculinity, based upon men being aggressive, stoic and homophobic (Pronger 1990). Yet, contemporary accounts of sportsmen suggest a changing or different understanding of masculinity in the athletic terrain (Dean 2013). Sociologist Eric Anderson has perhaps published the most research in this area (c.f.e. 2005a; 2005b; 2008; 2009; 2014; Anderson, Magrath and Bullingham 2016). In these, and many other studies, he proposes a softening of male gender in response to improved social attitudes toward homosexuality, especially among millennial males in Western cultures.

In examining men's fear of being socially perceived as homosexual, what Anderson (2009; 2011a) calls homohysteria, researchers evidence change in the gender performances of male athletes and non-athletes (McCormack 2012; Roberts 2014). Collectively, these authors agree with Anderson in stating that, as cultural antipathy towards homosexuality has reduced, many athletes no longer aspire to the traditional orthodox masculinity. Rather homophobia has lost its ability to police male gender in the western countries studied, and therefore multiple archetypes of masculinity can be esteemed without hegemony of any one (Anderson 2009). Accordingly, in contrast to men being hierarchically stratified, with men who embody orthodox masculinity at the top, Anderson $(2009 ; 2014)$ has found varying masculine archetypes are valued in an inclusive culture. It is therefore our contention that we can no longer accept as a null-hypothesis that contact sport athletes are homophobic, stoic, or even aggressive (Kreager 2007) without empirical evidence.

This research explores how masculinities are constructed within the context of Australian rugby league media, specifically the NRL Footy Show. Using Anderson's (2009) theoretical framework of inclusive masculinities, we examine how the Footy 
Show attempts to re-inscribe orthodox perspectives on masculinity, despite the more inclusive nature of masculinities among Australian Rugby League Players it features (Murray \& White 2015). We describe this juxtaposition by understanding the Footy Show as reflecting what Victor Turner (1967) called a liminal state. Turner (1969: 95) defined liminal entities as "neither here nor there; they are betwixt and between the positions assigned and arrayed by law, custom, convention, and ceremony'.

Consistent with liminality, we illustrate that this rugby league show is in a mid-point or liminal state in regards to masculinities; unable to present a coherent archetype of masculinity that is both based in historically acceptable forms of masculinity (and the culture of the show) and espoused by current players. In this case the players featured on the show no longer present evidence that they value all of the requisites of orthodox masculine proscription, while those that produce and direct the show, construct it to reify increasingly fleeting forms of athletic masculinity. Thus, the Footy Show presents conflicting messages about masculinity through its presentation of both orthodoxy and inclusivity.

\subsection{Inclusive Masculinities}

Anderson's (2009) Inclusive Masculinity Theory allows a contextually nuanced understanding of masculinities across time and context, primarily through its central concept of homohysteria (McCormack \& Anderson 2014a; 2014b). By accounting for a cultural understanding of homosexuality, and homophobia's utility to regulate male gender (Kimmel 1994), it is possible to evaluate why men perform in a manner to align to orthodox or more inclusive masculinities (Adams 2011; Anderson 2009; 2014; McCormack 2012; Roberts 2013).

Homohysteria is based upon the fear of being socially considered gay, therefore offering a dynamic understanding of the ebb and flow of homophobia for all men as a result of changing cultural attitudes towards and awareness of homosexuality 
(Plummer 2014). McCormack and Anderson (2014a; 2014b) postulate three components which impact the level of homohysteria in a culture. These are;1) cultural antipathy of homosexuality, 2) recognition of homosexuality as a legitimate sexual orientation that we are likely to come in contact with, and 3) the conflation of homosexuality with femininity.

A homohysteric culture is one that men fear being thought homosexual, primarily due to the social stigma attached to homosexuality (Herek 2004), which in turn forces them to actively distance themselves from behaviours socially constructed as feminine and thus gay. In a homohysteric environment, men are vertically stratified in a way that resonates with the theorising of Connell's (1995) hegemonic masculinity. She proposes that an orthodox archetype of heteromasculinity is culturally esteemed at the top of the gender order, holding hegemonic positioning. Other men have to either be complicit to this system, by attempting to associate with the esteemed version of masculinity, or face being subordinated primarily by being considered feminine, gay or both. Here, men continually compete for positioning at the top of this hetero-masculine hierarchy.

In this environment, orthodox masculinity holds the privileged position at the top of the gender order. David and Brannon's (1976) four rules of masculinity are a useful analogy for the understanding of orthodox masculinity, in that men must "be a sturdy oak", "be a big wheel”, "give 'em hell” and do "no sissy stuff”. Although David and Brannon's rules do not mention anything about compulsory heterosexuality; it is the cultural conflation of homosexuality with femininity, or "sissy stuff" in David and Brannon's words, that forces orthodox masculinity to be an opposition to the culturally subordinate homosexuality.

However, this becomes problematic for many men, primarily due to their inability to prove their heterosexual status. Anderson (2009: 95) contends, "in a 
homohysteric culture, heterosexual men are culturally incapable of permanently proving their heterosexuality". Boys and men are therefore socially required to use homophobia and exaggerated masculinity in an attempt to position them away from homosexuality, subsequently improving their place in the gender order (Connell 1995).

However, in times of improved social attitudes towards homosexuality, as seen in many western countries today (Keleher \& Smith 2012; Twenge et al. 2016), men no longer fear being socially perceived as gay and therefore homohysteria begins to wane. Homophobia is no longer a useful policing agent for the behaviours of many men in contemporary culture (McCormack 2012). Here, men are afforded an increasing range of acceptable gender performances, which captivate many of the behaviours previously only granted to women (Anderson 2009). This includes samesex cuddling, emoting and styling themselves in tight colourful clothing without being considered gay by friends or peers (Anderson \& McCormack 2014). Anderson (2009; 2014) and McCormack (2012) show these are not the only benefits to a culture with diminished homohysteria, with the acceptance of gay men also being widespread (Morris \& Anderson 2015).

In cultures of inclusivity, intra-male masculine hierarchies also transform as a result of reduced or diminished homohysteria (McCormack \& Anderson 2014). Rather than being hierarchically stratified, as described by Connell (1995) in homohysteric cultures; in a culture of inclusivity masculinities are more laterally aligned, with no masculine archetype holding hegemonic power over another (Anderson 2009; 2014; McCormack 2012). Inclusive masculinities are equally esteemed to the orthodox masculinities previously evidenced by masculinities scholars (Mac an Ghail 1994; Pronger 1990). Yet, it is important to highlight, inclusive masculinities are not proposing a postfeminist image of gender utopia 
(Anderson 2014), where men no longer hold patriarchal privilege. It is merely the recognition of multiple socially valued and legitimate masculine performances that have resisted the previous hegemonic and orthodox notion of heteromasculinity.

\subsection{Changing Masculinities in Sport}

In research of openly gay athletes in the United States, Anderson (2011b) found a change in the coming out narratives within their sports teams. Whereas athletes in the late 1990s would come out, often having to segment their homosexuality from their athletic identity, similar to that of the 'don't ask, don't tell' policies of the U.S. Army, or what Griffin (1998) describes as the glass closet, todays athletes are open and included among their teams (Adams et al. 2010; Magrath et al. 2015). This is true of both gay males and lesbian athletes in the United States and United Kingdom (Anderson et al. 2016). Openly and and lesbian athletes discussed their homosexuality with teammates and often engaged in open conversations about gay sex and relationships (Anderson 2011b).

Conveniently, in Adams and Anderson's (2012) ethnographic study of a university soccer team in the U.S., one athlete opted to come out to teammates, offering a unique and rich research event. Likewise, detailed and graphic discussions of homosexual sex were found between gay and straight teammates. Further literature on soccer supports this claim that homophobia is in decline on the playing field and among spectators (Adams et al. 2010; Cashmore \& Cleland 2011; 2012; Magrath et al. 2015) and thus it is possible that the positive environments found in both of the above studies (Adams \& Anderson 2012; Anderson 2011b) are not as a result of uniquely liberal research environments.

The discrepancy between sportsmen of varying cohorts is found in a number of studies. In their study on university soccer players, Adams et al. (2010) found resistance to the aggressive and violent discourses of soccer coaches. Anderson and 
McGuire (2010) found that misogynistic attitudes were absent amongst a team of British University Rugby players. This rugby team also evidenced personal resistance to the orthodox masculinity that their coaches embodied through various discourses, including gendered and anti-gay language (Anderson \& McGuire 2010). Similarly, White and Hobson (2015) found different age cohorts of physical educators had differing values and constructions of masculinity. Yet, many of the teachers could also provide numerous examples as evidence of their students opting for softer and more inclusive masculine performances (White \& Hobson 2015).

The softening of masculinities has also afforded athletes the ability to improve their homosocial relations, primarily via emotional openness and physical tactility (Anderson 2014; Anderson \& McCormack 2014). Emoting and the ability to be emotionally open are emerging as a key proponent of inclusive masculinities in times of reduced homohysteria (Anderson 2014; White \& Hobson 2015). These athletes are able to cry in public, support each other with emotional concerns, and they openly express their bromances (Magrath et al. 2015). Often, the young athletes even link their Facebook accounts claiming that they are in a relationship with their best friends. Scoats (2015) suggests this occurs as a symbol of emotional endearment and adds that they accompany it with photographs that demonstrate extreme physical tactility with each other. McCormack (2012) finds close friends greeting one another with expressions such as 'hey boyfriend' and that this accompanies multiple other forms of physical tactility in greeting. He and Anderson even show show 39/40 university athletes cuddling in bed with other males (Anderson \& McCormack 2014). Other research shows university men dancing intimately in nightclubs (Peterson 2011; Peterson \& Anderson 2012) and kissing their friends in public. Research on even younger boys, 16-18 year old British academy football players find many of these behaviours there, too (Roberts et al. in press). Supporting this body of research in 
Australia, recent research found $29 \%$ of heterosexual male Australian undergraduates, at one university, had kissed another man on the lips (Drummond et al. 2015).

\subsection{Male Bonding}

A culture of overt support does not, however, mean that the presence of a gay male athlete on a team (or television show about sport) might not disrupt the normal, homosocial, operation of an otherwise homogenous team. Masculinity studies have longdetermined that heterosexual masculinity is a front, which is essentially granted by other men (Kimmel 1994). Here, males seek the approval of other males, both identifying with and competing against them in order to raise their heteromasculine capital (Anderson 2005a). Much of this includes the playful, direct, overt and sometimes ironic establishment of one's heterosexuality through sexualised discourse and banter (Roberts et al. in press), which oftentimes includes men feigning gay sex with one another. Here, young heterosexual men - normally in private spaces like parties, hotel rooms and, most frequently, locker rooms - pretend to be sexually attracted to one another. In jest, they complement each other's bodies, or make jokes about being sexually attracted to their teammates. Still, it is highly common for homosocial groups of young straight men to pretend to give each other oral sex, and there is also a great deal of mock anal sex in these interactions (Anderson 2014).

This type of behaviour is widely documented in both interview and ethnographic research among adolescent, heterosexual team sport players on sex-segregated teams (Anderson 2005b; 2009; Anderson \& McGuire 2010) and can be interpreted many different ways. Most important to this paper, however, is that previous research on the experiences of openly gay men in sport (Adams \& Anderson 2012; Anderson et al. 2016) shows that mock gay sex, can also operate between straight and gay men, with the purpose of including gay men, and demonstrating support. Further exemplifying this, in a forthcoming article Anderson shows that among a group of 50 adolescent boys he 
coaches in California (with three openly gay teammates) straight athletes feign sexual interaction with gay athletes as a symbolic gesture of acceptance. Whereas some might interpret this as a mechanism of re/inscribing heterosexual power, or a mild form of homophobia, the gay male athletes on this team do not feel this way, nor do the straight male athletes articulate it as such. In McCormack's (2011) typology of homosexually themed language, it would be classified as a form of 'pro-gay language.' This is important because banter has been shown to be vitally important to the social processes of friendship-making among athletes, gay and straight alike (Anderson 2014). The unprovability of heterosexuality makes homogenous teams of young men ripe for banter about homosexuality. Importantly, banter is differentiated in both meaning and perceptual experience and this occurs via context and intent.

\subsection{Sport Media}

Sport media has been theorised has a primary site for the cultural reproduction of orthodox masculinity (Nylund 2007). This appears to be the case regardless of the sports medium or country. When covering men's sports, sports media emphasises male athletes' strength, ability to commit violence, stoicism, and other aspects of hardened masculinities (Billings 2007; Vincent et al. 2002).

One reason for the production of orthodox masculinity within sports media is because those who work within the institution tend to subscribe to this perspective of traditional conservative masculinity (Claringbould et al. 2004; Lapchick 2013). Due to their over-conformation to sporting norms (Anderson 2005a), Gee and Leberman (2011) suggests that a culture of conservative masculinity exists within both work routines and prominent gatekeepers, like producers and editors in the sport media industry.

The hyper-masculinisation of sport media is furthered by a lack of women within the industry. For example, Lapchick et al. (2006) have shown that sport media is run mostly by and for men. They surveyed more than 300 U.S. daily newspapers, finding 
that men comprised $95 \%$ of sports editors in newspaper sports departments, $87 \%$ of assistant sports editors, $93 \%$ of columnists, $93 \%$ of reporters, and $87 \%$ of copy editors/designers. David Nylund (2007) found that $80 \%$ of sports-talk radio hosts are men. Accordingly, Farred (2000: 101) described sports talk radio as 'overwhelmingly masculinist', and Smith (2002: 1) called it 'an audio locker room.'

Anderson (2005a) suggests that a further reason for the hyper-masculinisation of sport media is because those involved are failed male athletes. These are men who initially desire to be professional players and did not make it, or were once professional players and reel under the loss of their athletic identity (Anderson 2014). He suggests that sport reporters, more than anything, want to be one of the boys (meaning professional athletes). Thus, the industry does not attract those who take more critical perspectives on sport; and those of differing genders or sexualities are mostly kept-out by its gatekeepers.

However, some research on sport media is beginning to show changes from orthodox and toward inclusive masculinities. For example, in their research on the way sport media treated the coming out story of National Basketball Player John Amaechi, Kian and Anderson (2009) showed that print media writers exhibited little homophobia and frequently called for more acceptance of gays, particularly within sport. This is something that Kian et al. (2015) again found in a separate analysis of interviews with sport journalists. They expressed pro-gay attitudes with most expressing a reluctance to out a closeted gay athlete, even if this meant losing the story to a competitor.

In (2012), Anderson and Kian conducted a media analysis of Aaron Rodgers self-withdrawal, after suffering a head trauma, in an important NFL game. Rather than it being an enforced expectation for players to self-sacrifice their bodies, in alignment to traditional constructions of orthodox masculinity, many major sporting media outlets supported Rodgers in valuing his health over sport. 


\subsection{Method}

This research utilises a content analysis to examine how masculinities are constructed within Australia's premiere rugby league media program, the NRL Footy Show. The Footy Show airs every Thursday typically after 8.30pm Australian Eastern Time. It has run for 23 consecutive seasons since 1994 and usually involves three to four consistent co-hosts. These hosts are regularly supplemented with ancillary hosts who are current rugby league players and/or other athletes. Currently, the show has aired over 600 episodes with a running time of 90 minutes including television advertisements.

We chose three of these shows from the last completed season in 2010 for analysis. The shows aired on Channel 9, Thursdays at 9.30pm. We choose June 10 June, 17 June and $24^{\text {th }}$ to analyse. All three shows consisted of six segments punctuated by commercial breaks. The episode that aired on 10 June 2010 was a special charity show at Lennox Head, which ran for 1 hour 56 minutes, while the other two shows ran for 1 hour and 34 minutes each. These three episodes are available on free to air television, thus were available to be recorded within copyright laws. These shows are a standard reflection of the Footy Show's normative structure and content.

\subsection{Analytical Technique}

The NRL Footy Show episodes were examined via a content analysis of texts and visuals. Content analysis research often focuses on social problems and issues. It is therefore frequently used by gender theorists to explore inequality manifested by social structures (Van Dijk 2003). A content analysis was also selected because it is an unobtrusive and nonreactive tool used to measure communication messages (Macnamara 2003; Sparkes 1992). 
This type of methodology is, however, both interpretative and subjective (Harris \& Clayton 2002). Because multiple interpretations of the same text are possible (McKee 2001), two of the four researchers on this paper coded themes from the articles separately in the search for narratives. Working independently, the two researchers watched and wrote notes on the three shows.

The analysis examined the behaviours, language, dialogues, interaction and ultimately themes prominent amongst NRL Footy Show protagonists. The salient representations either verbal or physical were noted in the content analysis. They then compared and discussed coding of dominant themes for agreement (Emerson et al. 1995).

We then used Anderson's (2005b; 2009) concepts of orthodox and inclusive masculinities, as understood in his theory of inclusive masculinities, to guide our gendered analyses. We used this theory because it interrogates the social structures that enact, confirm, legitimate, reproduce, or impugn relations of power and dominance within male hierarchies. It does this by concentrating on the way social power, abuse, dominance, and inequality are enacted, reproduced and resisted through the show's texts and visuals.

\subsection{Denouncing Femininity}

Recent research on twelve Australian rugby football league players shows that they value inclusive masculinities and not orthodox notions of masculinity (Murray \& White 2015). For example, they evidence pro-gay sentiments, are emotionally open, dress in more feminine ways, and are unafraid to express feminine emotions or engage in feminine behaviors. However, this research on the NRL Footy Show finds some contrast in the performance of femininity by the show's presenters. The conceptualisation of desirable rugby masculinity lags behind the broader culture and the lived masculinity of the actual players. Instead, the show crafts an archetype of 
masculinity that is based in the traditional masculine characteristics of manliness, aggression, and anti-femininity (David \& Brannon 1976).

Evidencing this, men who presented themselves as more effeminate than the hosts were ridiculed. For example, a player who wore purple shoes was described as being 'fancy' and his shoes described as 'girlie'. It was suggested that he auction them off for charity. Another example comes from the mocking of a man in the crowd dressed up as Spiderman, specifically illuminated his peculiar attire which was accompanied by laughter. Another male with too many facial piercings was mocked for his perceived femininity and acerbically labelled as 'very handsome' by one of the presenters. The former being palpably laughed at while the latter being satirically referred to as 'very handsome'.

Sporting choices were policed through femphobia, too. Sports that the hosts considered less masculine than rugby were routinely mocked: soccer, surfing, dancing and even Australian Football League were targeted with femphobia. Soccer and Australian Football League players were particularly laughed at for being hit in the head with balls. This is demonstrated in a segment when they viewed Falcons which denotes when a ball unintentionally strikes a players head during a game. Instances of Falcons are depicted showing various clips from AFL and soccer games with the latter clips originating from Soccer world cup. Surfers were portrayed as 'drongos' and were labelled idiots who were poisoned and imitated as pretentions individual involved in asinine behaviour such as drug taking or cleaning a surfboard in the middle of the road. Additionally, dancers were so ridiculed they were viewed as a source of humour. For instance, two presenters who joined a dancing Michael Jackson impersonator were stated to move 'beautifully'.

Conversely, the rugby body was valorised for its masculine strength, and while this might be expected in a sport that requires such brutal force among athletes, 
the show extended this value onto children as well. For example, viewers send in videos of young boys' performances on the field, where presenters positively comment on their young strength more so than their skills. This segment traditionally rewarded the adolescent winner who was able to demonstrate physical dominance over other players. Such players were accompanied with awe and adulation. For instance, one young player was praised as being 'cool as a cucumber' for withholding emotions. Conversely, a coach and presenter were both disparaged for appearing nervous. The social conditioning of orthodox aspects of emotionality thus extended to both youth and professional rugby players.

For adults, presenters made comedic footage of off-field situations where someone's groin was struck, or where an individual was hit in the head by a wrench and was in considerable pain. Players were disparaged for being unable to control how they were affected by pain, which accords with the emotional detachment and lack of emotional expression required by orthodox masculinity (Wall \& Kristjanson 2005). Similarly, one presenter was teased for not being able to control his levels of perspiration, and presenters who appeared anxious or nervous were also mocked.

A presenter from the NRL Footy show who jokingly indicated fears specifically by hiding underneath a table to avoid a pending cyclone, was a source of ridicule. This denigration was repeated when a child (boy) from local primary school being interviewed about the approaching tornado reiterated the fearful sentiment by saying 'every man for themselves'. The child was laughed at; and was asked if he was related to the fearful presenter that hid underneath the table. Hence, the expressions of fear are viewed as a feminine trait, and therefore incompatible with manliness (Emslie et al. 2006) within the context of this show.

In line with one of David and Brannon's (1976) prescription of masculinity that of being a big wheel—being the 'main man' and 'doing the big plays' was touted 
as a major goal for players. Conversely, losing teams were scathingly attacked and dubbed 'deplorable'. Two Queensland presenters concurred that losing a State of Origin game to New South Wales was the 'darkest day in Queensland's history'. Denigration of loss in sport, and particularly emotional control, was also extended to control over the body. Loss of control of body weight was mocked, including pejorative references such as 'you're a monster' and 'giant of the sea', this control of body also extends to size and physical health. Wall and Kristjanson (2005) suggest that 'being a stud' who is physically fit is a defining characteristic of hegemonic masculinity. For example, two irregularly large men was revered for being big and muscular; conversely a presenter who is overweight was mocked for being obese. Bodily masculinity was further enacted through the feminisation of put-downs toward other men, one presenter saying 'at least I got one'- suggesting that lack of a penis was cause for scorn.

\subsection{Embracing Femininity}

However, the construction of orthodox masculinity via the hosts was not entirely dominating. There was some resistance to the orthodox notions of masculinity from the players who featured as guests. Many of these guests presented themselves in ways that we code as inclusive. For example, Most players dressed in extremely tight fitted clothing. Others wore more flamboyant outfits. For example, one player wore purple shoes and exhibited feminised body language. Although the presenters often mocked these behaviours, another player opted for stylish footwear. Similarly, another player was laughed at by the presenters for 'sunbaking' and caring about his personal appearance.

Guests also engaged in behaviours, or discussed activities, that are not compatible with orthodox notions of masculinity. Another practice that was downplayed was dancing, which was viewed as a source of humour, particularly 
emulating the effeminate style of Michael Jackson.. Another discussed his breeding of, not Rottweilers, but the highly effeminised labradoodles. This illustration involved a New South Wales State of Origin player who was quite burly, but who bred Labradoodles (the colloquial name for a breed that is a combination of Labradors and Poodles). The Footy Show suggested that the breeding of such non-masculine dogs was not appropriate for a masculine player stating 'You're a poodle breeder and you're playing State of Origin'. This paradox was justified by making the player's girlfriend accountable for the behaviour.

Players were also shown to exhibit emotions that are not consistent with orthodox masculinity. One discussed his team's losing as 'the darkest place to be'; another athlete stated 'losing is embarrassing', while others expressed themselves in a solemn and humble manner when they lost games. We recognise the importance of competition to orthodox masculinity, and thus losing is of course a challenge to their masculine identity. Yet, these men didn't respond with expressions of hypermasculinity to build masculine capital. Instead, they responded with soft emotional expression in public spaces: the expression of sadness, and on occasion, even vulnerability. These expressions were not limited to loss alone.

On two different occasions, the hosts collectively showed emotional vulnerability in regard to fatherhood and cancer. The first is when the hosts gave their well-wishes to Australian soccer player whose child was diagnosed with Leukaemia. Here, they evinced clear sadness and emotionality. The second was when a rugby league player's father died of cancer the previous year. Here, there was a palpable solemnness, and not a 'buck up' attitude. On the rarer occasion, the hosts even contested their own gender regime by contesting hyper-heterosexuality. For example, one presenter described one of the studio members as ' very handsome'. Another incident occurred where a comical scene played out where player was touching 
another player on the leg. The presenter was asked where on the leg he was being touched as the view of the offending hand was obscured. When the offending player was asked is there 'something we don't know about you', the player asserted his heterosexuality by stating emphatically, 'no, not me!'

It is important to remember that these activities are not spontaneous; they exist as scriptural agreements to conduct such actions on national television shows. This suggests that: 1) athletes are somewhat less concerned with being considered effeminate than the show's hosts; and 2) a good measure of the hosts masculine bravado is precisely as the title suggests, 'just show.'

\subsection{Objectification and Subordination of Women}

Disrespect for women and support for subordinating female practices is hallmark 'humour' on the Footy Show (Farrell 1999). For example, in one episode players were asked what they did not understand about women. In response, several players and coaches remarked that they did not understand women's need for vast closet space, shopping all the time, and taking a long time to get ready to go out. Sexual objectification was also used to disempower women. For example, in one episode, a comedian spoke about the sexual appeal of female Premiers (State leader similar to a governor in US or member of parliament in the UK) in New South Wales and

Queensland. He dismissed the Queensland Premier state leader as sexually unappealing but stated, with regard to New South Wales' Premier and former governor, that he 'would go that', suggesting he would like to have sex with the politician. The comedian continued to comment that the famous philandering cricketer, Shane Warne, knows how to treat women because he would text his wife to clean the house and feed the dog, then tell her to 'piss off'. This segment thus both objectified powerful female politicians and subjugated women as servants to men. 
In another example, the female disk jockey of the show, DJ Cindy, was continually subjected to sexual objectification. When introduced, she endured wolf whistling and taunts from the audience. Additionally, she was used to model team jerseys, with one presenter instructing players to 'get her and her hot body into that jumper'. She was later viewed erotically dancing, which was applauded by the crowd. Another segment showed a player and co-host, Beau Ryan, in bed with a woman who the player appeared to be teaching to have sex. During this segment, the player showed his dominance over the woman by stating that he 'wanted plenty of good ball work' and by stopping during sex for what he termed 'half time' to have a sport drink and oranges. In a further instance, showed an attractive, slim, scantily-clad woman, about which one presenter remarked, 'not wearing much there, she looks good'. Other, more subtle, examples occurred where women appeared as masseurs for players or mute spokes models, silently conveying their roles as servants to men, possessing primarily aesthetic value, but not conversational importance.

These forms of sexism are more difficult for guests to contest. They are scripted and approved by the show, and out of remit of the players. Thus, contesting sexism in these segments was not often possible. Yet, resistance did occasionally emerge. For example, there was one female presenter, Roz Kelly, who regularly conversed with presenters and players by relating news stories. However, she was sexualised, and was regularly subordinated and objectified. She was solicited on one occasion to sexualise men. Here, a male presenter asked her if men who wear pink look 'hot' but perhaps in opposite of what the male presenters expected, she affirmed that they did. In another show a player attributed his success to his girlfriend, for which he was mocked, specifically laughed at and viewed as comical by the audience and fellow presenters.

\subsection{Heteronormativity and Homophobia}


In line with Anderson's (2005b) notions of orthodox masculinity, the show's hosts promoted hyper-heterosexuality among rugby players. They introduced the episode's guests (rugby players) at the start of the show and, in each episode, showed attractive female audience members, the implication being that attractive women are interested in current NRL players.

Conversely, male homosexuality was mocked. For example, one player was ridiculed when caught looking at images of another player in his underwear. After the player is caught looking he said, 'I know it's disgusting' which is accompanied by laughter from the audience. Another episode featured two players shown naked in a bath, and here their behaviour was overtly depicted as unacceptable. One of the players in the bath pretended to vomit at the sight of seeing the other man naked. There was also a live cross to two players at a piano bar that suggested the men were enjoying a romantic candlelit dinner, which was deprecated through homosexualising innuendo; suggesting that male homosexuality is denigrated and should be avoided. In another show, a presenter jokingly made a specious advance to another male presenter who retorted with 'don't look at me like that', at the same time kissing his wedding ring to reinforce his heterosexuality. Another scene of the show featured a comical mocking of gay men by showing one player touching another player on the leg. The presenter was asked where on the leg he was being touched as the view of the offending hand was obscured. When the offending player was asked is there 'something we don't know about you?' the player asserted his heterosexuality by stating emphatically, 'No. Not me!'

The illustration of this conduct is however specious. Humour rather than homophobia underlies the actions of the host and players on the footy, particularly in a cultural moment in which young male athletes identify some element of bisexuality within their own identities (Anderson \& Adams 2011). Our interpretation of the intent 
is that it is designed to be funny, semi-ironically demonstrating the acceptance of gay banter, rather than to demonise homosexuality. Exemplifying this, there were no recorded instances of matter-of-fact homophobia. Hosts did not denounce homosexuality outside of humour. Anti-gay messages can only be coded through humour, leaving them open to subjective interpretation. In other words, these skits can be misconstrued as actions of overt homophobia, but they can also be examined through a lens of show. In fact, one could argue that the mere addition of these skits and comments demonstrates a gay friendliness which previously would never be included. After all, the two players agreed to be filmed in a bath tub together.

\subsection{Promotion of Violence}

Finally, in line with orthodox masculinity, discourses of aggression saturated the NRL Footy Show. Violence, fighting, confrontation and belligerence were common themes in the episodes analysed. This is something that Anderson (2014) suggests still exists as part of many collision sports, even in studies of young men who otherwise exhibit inclusive aspects of masculinity.

Evidencing the lore of violence in this professional sport, during one episode a dangerous tackle and head-butting incident between two star players of the NRL (Billy Slater and Jarred Hayne) resulted in a team brawl. Instead of this behaviour being admonished, the hosts condoned it, which was further endorsed by the crowd applause when replaying brawling or fighting vision. A player involved in a separate fight, who was jabbed in the face whilst being restrained by other players, commented on the incident by verballing reconciling, 'Them things happen' and that it 'makes it a great game'. Even here, however, some differences between hosts and players emerged. When interviewed about the fracas, the players only conditionally endorsed it, claiming that it was 'good media' and that people 'loved talking about it'. However, the presenters promoted the violence through asking the public their 
opinions as well as getting demonstrations of the head butt with mannequin doll heads.

Promotion of violence by the show also came through the continual broadcasting of rugby violence when it occurred. The footage of several melees were shown at the conclusion of one show. Violence was also valorised when constructed as protecting one's friends. The most notable example of this occurred when a player justified violence against someone who threatened a team player, as teammates were akin to brothers and protecting each other was regarded as a legitimate justification for violence. Presenters also praised players for running in and protecting teammates in fights.

Breaching rules and taking risks was also condoned within the discourse of the show. For example, in the Jarryd Hayne head-butt, rule-breaking was condoned and legitimised. There was also denigration of an apology by a player who was contrite about swearing at match officials. However, this player concluded his apology with the flippant recommendation that respecting referees will lead to more favourable treatment, virtually rendering the apology tokenistic. Risk taking was exalted by the presenters who praised players as courageous when they threw themselves back into games without thinking of self-perseveration and personal safety.

By suggesting violent incidents are 'good media', and apologising for swearing, these players are both supporting and contesting orthodox masculinity But this is also one area where players are less inclined to protest the hosts: this sport remains violent, despite the more inclusive attitudes of its players.

\subsection{Discussion}

It is also important to acknowledge that the orthodox behaviours demonstrated by the hosts may not necessarily reflect their personal attitudes towards masculinity. 
Although the host's behaviours may appear authentic, scripting can be manipulated to create this impression of informality and authenticity (Ytreberg 2006). In reality, the host may be subject to playing a particular 'role' or 'character'; created by the makers of the show, and influenced through the institutional norms around masculinity in sports media (Claringbould et al. 2004; Lapchick 2013). It is therefore difficult to determine the extent to which the hosts have agency, or whether their behaviours have stemmed from a lack thereof.

The aim of this research was to explore, through the use of a content analysis, constructions of masculinity within the NRL Footy Show, and to distinguish legitimised from relegated or subordinate masculinities. Results revealed that the show's hosts, in both words and skits, reified orthodox masculinity through the promotion of stoicism, violence, sexism and homophobia. Male behaviours deemed outside these points of reference (e.g. losing, lack of control, being effeminate or gay) were thereby relegated and subordinated. This finding suggests that, by virtue of its writers, creators, and potentially the hosts themselves, orthodox masculine ideals pervade the NRL Footy Show.

However, all is not total here. The guests (whom are younger men) tended to only speciously conform to performances of orthodox masculinity. They did not utterly and completely subscribe to orthodox masculinity. Contestation came though the expression of feminised emotions, attire, and the willingness for players to be mocked. It is also important to acknowledge that the orthodox behaviours demonstrated by the hosts may not necessarily reflect their personal attitudes towards masculinity. Although the host's behaviours may appear authentic, scripting can be manipulated to create this impression of informality and authenticity (Ytreberg 2006). In reality, the host may be subject to playing a particular 'role' or 'character'; created by the makers of the show, and influenced through the institutional norms around 
masculinity in sports media (Claringbould et al. 2004; Lapchick 2013). It is therefore difficult to determine the extent to which the hosts have agency, or whether their behaviours have stemmed from a lack thereof.

Thus our content analysis reveals that there is a generational divide between the old proponent's orthodox masculinity and the young's inclusive masculinity. The show seems intended to appeal to those socialised in an era where extreme phobia was compulsory to achieve masculinity. This culture of relative orthodoxy, however, stands in contrast to the younger athletes appearing on the show who were cultivated in an era more acceptable of homosexuals and feminine practices. Anderson (2014), as well as White and Hobson (2015) find this in their research as well: players exhibiting inclusive masculinities while coaches (whom are older) value orthodox masculinity. Yet, this is not to say that the makers of the show harbour antipathy toward homosexuality. There is not direct, overt, categorical statement against homosexuality. Instead, homosexuality is joked about; and this makes it harder to read intent.

Complicating intent, masculinity studies have long-determined that heterosexual male friendships are established and promoted through banter. This banter includes the playful, direct, overt and sometimes ironic establishment of one's heterosexuality through sexualised discourse and banter, which oftentimes includes men feigning gay sex with one another (Diamond et al. 2000; McCormack 2012). Anderson (2014) shows that this homosexualised banter continues on teams even after a gay player comes out; in fact, it intensifies. Hence, poking at guests' sexuality serves a form of communal bonding between players and the show's hosts. The skits performed, and comments made about homosexuality, or banter about things associated with homosexuality (like high fashion), are intentional ploys to both relate 
to common bonding techniques among men; as well as performed in the name of humour.

This type of behaviour is widely documented in both interview and ethnographic research among adolescent, heterosexual team sport players on sexsegregated teams (Anderson 2005b; 2008; 2009; 2014; Anderson \& McGuire 2010; Flood 2008) and can be interpreted many different ways. One could, for example, view it as a homophobic mocking of gay men, while others might prefer to view it as a method for ironically showing that one is not gay in a culture of homohysteria (Anderson et al. 2012). Still others view it as a mechanism for the degradation of women (Sedgwick 1985).

The view we think most aptly suits this research however, comes through McCormack and Anderson (2010), who describe this as a form of ironic heterosexual recuperation —where men ironically proclaim same-sex desire to consolidate their heteromasculine standing. Crucially, they argue, that this is a way that heterosexual men prove their masculinity without being homophobic. This, they argue is necessary, because unlike gay men who are socially accepted (believed) to be gay upon proclamation, the same does not hold true of heterosexual men (McCormack 2011).

These gay-themed narratives thus add weight to the argument that the Footy Show is in a state of liminality. In this context, liminality can be tersely described as intermediate state phase or condition. It could be interpreted that the NRL Footy show is transitioning between archaic orthodox masculinities values and slowly moving to one of more inclusive masculinities. Whether we view the show as being in a liminal state or not will depend upon whether one believes it will continue to transition further, or whether its current state will still allow for it to be popular within a culture of growing inclusivity. 
Building upon the latter direction, another interpretation could be that the makers of the show recognise that the audience no longer universally values orthodox masculinity, nor is it exalted by the players they feature on the show. It is for this reason that the show aims to shape a version of appropriate masculinity through humour. The show can be viewed as resistance against growing cultural trends of softening masculinity. The facetious framework structurally imposed on the show manner suggests that all involved know that misogynistic and homophobic statements are now socially unacceptable (and those reading homophobia into the text make a specious argument). Therefore, the humour allows for plausible deniability in their propositions. Thus, this strategy enables the show to straddle the intergenerational divide: reinforcing traditional masculinity to those with more orthodox proclivities, whilst at the same time couching their activities/language in humour that allows for the younger generation to interpret them as innocuous banter. It should be noted that there, of course, will be members of the older generation whom adopt inclusivity (and vice-versa), but it is the younger generation that most consistently demonstrate this (Anderson 2014).

The implications of this phenomena are that a show is not a literal sense of masculinity but instead symbolic representation of diminishing masculinities. The host and players of the show act in this way for theatre and entertainment value, but largely do not maintain those views/behaviours outside of this televised medium. Similar to other men's show such as Top Gear in the United Kingdom and the Man Show in the US, in order to fully understand the show, we must look beyond what is being said and to the meanings and functions surrounding the complexity of masculine behaviours.

\subsection{References}


ADAMS, A (2011) 'Josh Wears Pink Cleats': Inclusive Masculinity on the Soccer Field. Journal of Homosexuality Vol. 58, No. 5, p. 579-596.

ADAMS, A. \& Anderson, E (2012) Exploring the Relationship Between Homosexuality and Sport Among the Teammates of a Small, Midwestern Catholic College Soccer Team. Sport, Education and Society Vol. 17, No.3 p. 347-363.

ADAMS, A, Anderson E \& McCormack M (2010) Establishing and Challenging Masculinity: The Influence of Gendered Discourses in Organized Sport. Journal of language and social psychology Vol. 29, No. 3, p.278-300.

ANDERSON, E (2005a) In the Game: Gay Athletes and the Cult of Masculinity. New York:

State University of New York Press.

ANDERSON, E (2005b) Orthodox and Inclusive Masculinity: Competing Masculinities Among Heterosexual Men in a Feminized Terrain. Sociological Perspectives, Vol. 48, No 3, p. 337-355.

ANDERSON, E (2008) 'Being Masculine is Not About Who You Sleep With...:' Heterosexual Athletes Contesting Masculinity and the One-time Rule of Homosexuality. Sex Roles, Vol. 58, No 1-2, p. 104-115.

ANDERSON, E (2009) Inclusive Masculinity: The Changing Nature of Masculinities. London: Routledge.

ANDERSON, E (2011a) The Rise and Fall of Western Homohysteria. Journal of Feminist Scholarship, Vol. 1, No. 1 p. 80-94.

ANDERSON, E (2011b) Updating the Outcome Gay Athletes, Straight Teams, and Coming Out in Educationally Based Sport Teams. Gender \& Society, Vol. 25, No. 2, p. 250268.

ANDERSON, E (2014) 21st Century Jocks. Basingstoke: Palgrave MacMillan. 
ANDERSON, E \& Adams A (2011) “Aren't We All a Little Bisexual?”: The Recognition of Bisexuality in an Unlikely Place. Journal of Bisexuality, Vol. 11, No. 1, p 3-22.

ANDERSON, E, Adams A \& Rivers I (2012) 'I Kiss Them Because I Love Them': The Emergence of Heterosexual Men Kissing in British Institutes of Education. Archives of Sexual Behaviour Vol. 41, No. 2, p. 421-430.

ANDERSON, E \& Kian E M (2012) Examining Media Contestation of Masculinity and Head Trauma in the National Football League. Men and Masculinities, Vol. 15, No. 2, p.152-173.

ANDERSON, E, Magrath R \& Bullingham R (2016) Out in sport: The experiences of openly gay and lesbian athletes. London: Routledge.

ANDERSON, E \& McCormack M (2014). Cuddling and Spooning: Heteromasculinity and Homosocial Tactility among Student-athletes. Men and Masculinities. [doi:10.1177/1097184X14523433]

BILLINGS, A C (2007). From Diving Boards to Pole Vaults: Gendered Athlete Portrayals in the "Big Four" Sports at the 2004 Athens Summer Olympics. Southern Communication Journal, Vol. 72, No. 4, p. 329-344.

CASHMORE, E \& Cleland J (2011) Glasswing Butterflies: Gay Professional Football Players and Their Culture. Journal of Sport \& Social Issues Vol. 35, No. 4, p. 420436.

CASHMORE, E \& Cleland J (2012) Fans, Homophobia and Masculinities in Association Football: Evidence of a More Inclusive Environment. British Journal of Sociology Vol 63, No. 2 p. 370-387.

CLARINGBOULD, I, Knoppers A \& Elling A (2004) Exclusionary Practices in Sport Journalism. Sex Roles Vol. 51, No. 11-12, p. 709-718. 
DAVID, D S \& Brannon R (1976) The Forty-nine Percent Majority: The Male Sex Role. Reading, MA: Addison Wesley.

CONNELL, R W (1995) Masculinities. St. Leonards: Allen \& Unwin.

DEAN J J (2013) Heterosexual Masculinities, Anti-homophobias, and Shifts in Hegemonic Masculinity: The identity Practices of Black and White Heterosexual Men. The Sociological Quarterly Vol. 54, no. 4, p. 534-560.

DIAMOND D, Kimmel M S \& Schroeder K (2000) What's This About a Few Good Men?: Negotiating Gender in Military Education in Lesko N (eds.) Masculinities at School: Research on Men and Masculinities. London: Sage.

DRUMMOND, M, Filiault S, Anderson E \& Jeffries D (2015) Homosocial Intimacy among Australian Undergraduate Men. Journal of Sociology. Vol. 51, No. 3, p. 643-656.

EMERSON, R M, Fretz RI \& Shaw LL (1995) Writing Ethnographic Fieldnotes. Chicago: University of Chicago Press.

EMSLIE C, Ridge D, Ziebland S \& Hunt . (2006) Men's Accounts of Depression: Reconstructing or Resisting Hegemonic Masculinity? Social Science and Medicine Vol. 62, p. 2246-2257.

FARRELL K (1999) (Foot)ball Gowns: Masculinities, Sexualities and the Politics of Performance. Journal of Australian Studies Vol .23, No. 64, p. 157-164.

FARRED G (2000). Cool as the Other Side of the Pillow: How ESPN's Sportscenter has Changed Television Sports Talk. Journal of Sport \& Social Issues, Vol. 24, No. 2, p. 96-117.

FLOOD M (2008) Men, Sex, and Homosociality: How Bonds Between Men Shape Their Sexual Relations with Women. Men and Masculinities Vol. 10, No. 3, p. 339-359. 
GEE, B L \& Leberman S I (2011) Sports Media Decision Making in France: How They Choose What We Get to See and Read. International Journal of Sport Communication Vol. 4, No.3, p. 321-343.

GHAILL, M A (1994) The Making of Men: Masculinities, Sexualities and Schooling. McGraw-Hill Education (UK).

GRIFFIN, P (1998). Strong Women, Deep Closets: Lesbians and Homophobia in Sport. Leeds: Human Kinetics Publishers.

HARRIS, J \& Clayton B (2002) Femininity, Masculinity, Physicality, and the English Tabloid Press: The case of Anna Kournikova. International Review for the Sociology of Sport, Vol. 37, p. 397-414.

HEREK, G M (2004) Beyond "Homophobia": Thinking About Sexual Prejudice and Stigma in the Twenty-first Century. Sexuality Research \& Social Policy, Vol. 1, No. 2, p. 6-24.

KELEHER, A \& Smith E (2012) Growing Support for Gay and Lesbian Equality Since 1990. Journal of Homosexuality Vol. 59, No 9. p. 1307-1326.

KIAN, T \& Anderson E (2009). John Amaechi: Changing the Way Sport Reporters Examine Gay Athletes. Journal of Homosexuality Vol. 56, No. 7, p. 799-818.

KIAN, E M, Anderson E, Vincent J \& Murray R (2015) Sport Journalists' Views' on Gay Men in Sport, Society, and within Sport Media. International Review for the Sociology of Sport Vol. 50, No. 8, p. 895-911.

KIMMEL, M S (2004) Masculinity as Homophobia: Fear, Shame, and Silence in the Construction of Gender Identity in Rothenberg P S (Eds.) Race, Class, and Gender in the United States: An integrated study. New York: Worth.

KREAGER D A (2007) Unnecessary Roughness? School Sports, Peer Networks, and Male Adolescent Violence. American Sociological Review Vol. 72, No. 5, p. 705-724. 
LAPCHICK R (2013) The 2012 Associated Press Sports Editors racial and gender report card.University of Central Florida, Institute for Diversity and Ethics in Sport. Accessed 26 March 2013 from: <http://www.tidesport.org/RGRC/2012/2012_APSE_RGRC.pdf>

LAPCHICK, R, Brenden J \& Wright B (2006). The 2006 Racial and Gender Report Card of the Associated Press Sports Editors. Accessed October 222007 from: $<$ http://www.bus.ucf. edu/sport/public/downloads/2006_Racial_Gender_Report_Card_AP_Sports_Editors.p df $>$

MAGRATH, R, Anderson E \& Roberts S (2015) On the Door-step of Equality: Attitudes Toward Gay Athletes Among Academy-level Footballers. International Review for the Sociology of Sport, Vol. 50, No. 7, p.804-821.

MACNAMARA, J (2003) Mass Media Effects: A Review of 50 Years of Media Effects Research. Accessed July 302004 from: $<$ http://www.archipelagopress.com/jimmacnamara> MCCORMACK, M (2011) Mapping the Terrain of Homosexually-Themed Language. Journal of Homosexuality Vol 58 No. 5 p. 664-679.

MCCORMACK, M (2012) The Declining Significance of Homophobia: How Teenage Boys are Redefining Masculinity and Heterosexuality. Oxford: University Press.

MCCORMACK, M \& Anderson E (2014a) The Influence of Declining Homophobia on Men's Gender in the United States: An Argument for the Study of Homohysteria. Sex Roles. Vol. 71, No. 3-4, p. 109-120.

MCCORMACK, M \& Anderson E (2014b) Homohysteria: Definitions, Context and Intersectionality. Sex Roles, Vol 71, No 3-4, p. 152-158.

MCKEE, A (2001) A Beginner's Guide to Textual Analysis. Metro: Media \& Education Magazine Vol. 127-128, p.138-149. 
MORRIS, M \& Anderson E (2015) 'Charlie Is So Cool Like': Authenticity, Popularity and Inclusive Masculinity on YouTube. Sociology. [doi: 10.1177/0038038514562852] MURRAY, A \& White A (2015) Twelve Not so Angry Men: Inclusive Masculinities in Australian Contact Sports. International Review for the Sociology of Sport. [doi:1012690215609786]

NYLUND, D (2007) Beer, Babes, and Balls. New York: University Press.

PETERSON, G. (2011) Clubbing Masculinities: Gender Shifts in Gay Men's Dance Floor Choreographies. Journal of Homosexuality Vol. 58, No. 5 p. 608-625.

PETERSON, G \& Anderson E (2012) The Performance of Softer Masculinities on the University Dance Floor. The Journal of Men's Studies Vol. 20, No. 1 p. 3-15. PLUMMER, D (2014) The Ebb and Flow of Homophobia: A Gender Taboo Theory. Sex Roles Vol. 71, No. 3-4, p. 126-136.

PRONGER, B (1990) The Arena of Masculinity: Sports, Homosexuality, and the Meaning of Sex. New York: St. Martin's Press.

ROBERTS S (2013) Boys will be Boys...Won't They? Change and Continuities in Contemporary Young Working-class Masculinities. Sociology Vol. 47, No. 4, p.671686.

ROBERTS, S (2014) Debating Modern Masculinities: Change, Continuity, Crisis? Basingstoke: Palgrave.

ROBERTS, S, Anderson E \& Magrath R (In Press). Inclusive Masculinity in the Man's Game: Continuity, Change and Complexity in the Performance of Masculinity Among Elite Young Footballers. British Journal of Sociology.

SCOATS, R (2015) Inclusive Masculinity and Facebook Photographs Among Early Emerging Adults at a British University. Journal of Adolescent Research, [doi:0743558415607059] 
SEDGWICK, E K (1985) Between Men: English Literature and Homosocial Desire. New York, NY: Columbia University Press.

SPARKES, A (1992) Validity and the Research Process: An Exploration of Meanings. The Physical Education Review Vol. 15, No. 1, p. 29-45.

TURNER, V (1967) Betwixt and Between: The Liminal Period in Rites de Passage. The Forest of Symbols. Cornell: University Press.

TURNER, V (1969) The Ritual Process: Structure and Anti-structure. Chicago: Aldine Pub.

TWENGE J M, Sherman R A \& Wells B E (2016) Changes in American Adults' Reported Same-Sex Sexual Experiences and Attitudes, 1973-2014. Archives of Sexual Behaviour, [doi: 10.1007/s10508-016-0769-4]

VAN DIJK, T A (2003) Critical Discourse Analysis in D. Schiffrin, Tannen D \& Hamilton H E (eds.) The Handbook of Discourse Analysis ( $3^{\text {rd }}$ edition). Malden: Wiley Blackwell.

VINCENT, J, Imwold C, Masemann V \& Johnson JT (2002) A Comparison of Selected "Serious" and "Popular" British, Canadian, and United States Newspaper Coverage of Female and Male Athletes Competing in the Centennial Olympic games. International Review for the Sociology of Sport Vol. 37, No. 3-4, p. 319-335.

WALL, D \& Kristjanson L (2005) Men, Culture and Hegemonic Masculinity: Understanding the Experience of Prostate Cancer. Nursing Inquiry Vol. 12, No. 2, p. 87-97. WHITE, A \& Hobson M (2015) Teachers' Stories: Physical Education Teachers' Constructions and Experiences of Masculinity Within Secondary School Physical Education. Sport, Education and Society, [doi:10.1080/13573322.2015.1112779] YTREBERG, E (2006) Premeditations of Performance in Recent Live Television. European Journal of Cultural Studies Vol. 9, No. 4, p. 421-440. 
